\title{
A dependência da arrecadação do município de Ouro Preto do setor mineral
}

\author{
The dependency of mineral revenues \\ in Ouro Preto municipality
}

\section{Celso Guimarães Carvalho \\ Advogado, Mestrando no Programa \\ de Pós-Graduação em Engenharia Mineral, \\ Escola de Minas, UFOP. \\ celso.carvalho@ouropreto.mg.gov.br}

José Margarida da Silva

Engenheiro de Minas, Doutor,

Programa de Pós-Graduação em Engenharia

Mineral, Escola de Minas, UFOP.

jms@demin.ufop.br

\section{Adilson Curi \\ Engenheiro de Minas, Doutor, Programa de Pós- \\ Graduação em Engenharia Mineral, \\ Escola de Minas, UFOP. \\ curi@demin.ufop.br}

\section{José Cruz do Carmo Flores}

Engenheiro de Minas, Doutor,

Programa de Pós-Graduação em Engenharia

Mineral, Escola de Minas, UFOP.

jcruzflores@demin.ufop.br

\section{Resumo}

A promoção da atividade mineral pode proporcionar um impulso à arrecadação municipal, permitindo que seja prestado um serviço público de qualidade à população e fomentando uma fonte de financiamento para o desenvolvimento local. O conhecimento do grau de dependência da arrecadação municipal das receitas provenientes das atividades da mineração é uma necessidade para os municípios denominados mineradores, que devem acompanhar as reservas e a produção desses recursos e se preparar para a temporalidade e a flutuação de preços do mercado das commodities minerais. Assim, é imprescindível que políticas públicas sejam adotadas com o objetivo de ampliar a matriz produtiva do município, através da prática de uma política tributária em consonância com as características da economia mineral local. Esse artigo analisa a situação da dependência da arrecadação do município de Ouro Preto da mineração e apresenta perspectivas para a discussão do tema.

Palavras-chave: Economia mineral, tributação mineral, município, desenvolvimento.

\section{Abstract}

The promotion of the mining industry can be an opportunity for the local government to improve revenue, allowing for more possibilities to provide public services of quality to the population; it is a financial source for local development. Knowledge of the dependency level of the local revenue derived from mining activities is necessary for mining-based municipalities. Monitoring of reserve levels and ore production is a way to get prepared for the temporality of the mineral industry and the fluctuation of the commodities market. Thus, it is indispensable that public policies be provided to diversify the local economy and to elaborate a tax policy consistent with the characteristics of the local mineral economics. This study analyzes the situation of the mining revenue dependency of the Ouro Preto municipality as compared with other municipalities and then introduces perspectives for debate.

Keywords: Mineral economics, mineral revenue, local government, development. 


\section{Introdução}

A mineração é uma atividade econômica essencial, sendo, mesmo, de interesse público, produzindo bens primários, que irão suprir as mais variadas atividades econômicas, desde a agricultura até indústrias de tecnologia de ponta. Além disso, a mineração tem papel decisivo para muitas economias cuja base está assentada na extração dos recursos minerais.

A atividade extrativa mineral de larga escala impacta sobremaneira a vida dos municípios que têm a mineração na base de sua organização político-financeira e social. Tal fato decorre das próprias características técnico-econômicas do setor, das quais se destacam a rigidez locacional e a exauribilidade das jazidas (Herrmann, 2000).

A rigidez locacional está relacionada ao fato de que a localização da jazida, que irá definir o local de implantação da lavra, independe da ação humana. Em função dessa característica, o município onde se situa o empreendimento mineral irá, necessariamente, receber os bônus e arcar com os ônus da extração e bene- ficiamento dos recursos minerais, tais como problemas decorrentes da degradação ambiental e a dependência econômica do setor extrativo. Por outro lado, receberá benefícios como a participação na arrecadação de royalties e tributos.

$\mathrm{O}$ aspecto da exauribilidade da jazida é outro fator que deve ser considerado no impacto produzido pela mineração, uma vez que os recursos minerais, assim como seus resultados econômicos para a sociedade, têm um caráter finito.

Em função dessas características, há a aceitação, quase generalizada, da idéia de que a mineração deve ser taxada de maneira adicional, pois, ao utilizar um recurso da coletividade, deve compensá-la pela perda permanente daquele bem (Monteiro, 2004).

O conhecimento do grau de dependência da arrecadação municipal das receitas provenientes da extração mineral é uma necessidade para os municípios mineradores. Em função da exauribilidade das jazidas e da grande flutuação do mercado de commodities, o acompanhamento e a busca pela ampliação das fontes de receitas devem nortear o planejamento da administração municipal.

Ouro Preto está localizado no interior do polígono conhecido como "Quadrilátero Ferrífero", importante província mineral situada no Estado de Minas Gerais, possuindo uma produção mineral diversificada (Ferro, Dolomito, Calcário, Talco, Manganês Gemas, Rochas e Cascalho) (Fundação João Pinheiro, 2009). Segundo a Fundação João Pinheiro, a reserva medida de minério de ferro existente no município de Ouro Preto, no ano base de 2005, era de 1.850.575.719 toneladas, situando-o como o maior detentor de reservas desse bem mineral no Estado de Minas Gerais. Já a produção bruta de minério de ferro, no mesmo ano base de 2005, foi de 8.336.114 toneladas, posicionando o município como o $10^{\circ}$ maior produtor do Estado (Fundação João Pinheiro, 2009).

O propósito desse trabalho é o de analisar e mensurar as rendas do município de Ouro Preto provenientes do setor mineral e discutir os desafios da dependência da arrecadação desse setor.

\section{Tributos e outras receitas municipais}

A Constituição da República, ao estabelecer a competência tributária, reserva à exclusiva competência municipal instituir e arrecadar: 1) Imposto predial e territorial urbano (IPTU); 2) Imposto sobre transmissão "inter vivos", a qualquer título, por ato oneroso, de bens móveis, por natureza ou acessão física, e de direitos reais sobre imóveis, exceto os de garantia, bem como cessão de direitos à sua aquisição (ITBI); 3) Imposto sobre serviços de qualquer natureza (ISS), não compreendidos no art. 155, II, definidos em lei complementar (CF, art. 156).

Esses são os impostos privativos do município, que visam a proporcionar a esse ente da Federação condições de buscar a sua autonomia financeira, arrecadando tributos de sua competência exclusiva. Além desses impostos privativos, o município participa da arrecadação dos impostos de outros entes (União e Estado-Membro), os quais são denominados de impostos partilhados. Consideram-se impostos partilhados aqueles que a Constituição determina que um ente federativo deva partilhar do produto da arrecadação de determinados tributos de outro (Carrazza, 2004).

Cumpre destacar que a partilha é parcial, representada pelas quotaspartes que a Constituição prescreve que sejam distribuídas aos municípios. Essa partilha, em regra, não pode sofrer retenção ou qualquer restrição à entrega e ao emprego (CF, art. 160). Relacionada à produção mineral está a transferência do Imposto Sobre Operações Relativas à Circulação de Mercadorias (ICMS).
Finalmente, é assegurada aos municípios, a partir da Constituição Federal de 1988, a compensação financeira pela extração de recursos minerais $(\mathrm{CF}$, art. 20 , inc. IX, $\left.\$ 1^{\circ}\right)$, que ocorre através da Compensação Financeira pela Exploração Mineral (CFEM).

Tendo em vista que o objeto de estudo desse trabalho é a análise das rendas provenientes da atividade mineral destinadas aos municípios, serão destacadas apenas aquelas que se relacionam com o tema, quais sejam: o ISS, o ICMS e a CFEM. No entanto, cabe destacar que ainda incidem sobre a produção mineral o Imposto de Renda e as contribuições para a seguridade social (COFINS, PIS/PASEP e Contribuição Social Sobre o Lucro Líquido), todos de competência tributária da União.

\section{Imposto sobre serviços de qualquer natureza - ISS}

Nos termos do art. 156, III da Constituição, o ISS incide sobre os serviços de qualquer natureza não compreendidos no art. 155, II da Constituição, definidos em lei complementar, ou seja, cabe ao município instituir imposto sobre serviços, desde que esses não estejam na esfera de competência do ICMS e que estejam definidos em lei complementar, atualmente a Lei Federal Complementar 116/2003.

A Lei Complementar 116/2003 traz, em seu bojo, os dispositivos que configuram o fato gerador e a base de cálculo do ISS, enumerando em uma lista anexa quais são os serviços sobre os quais irá incidir. A lista é taxativa, logo o município não pode lançar o ISS sobre serviços não constantes da mesma. Incluem-se aí serviços prestados a mineradoras.

A efetividade da prestação do ser- 
viço é requisito para a constituição da obrigação tributária, dado o fato gerador que se materializa na prestação e na base de cálculo, cuja regra é o preço do serviço prestado.

Exceção à regra da cobrança do preço do serviço é o estabelecimento de tributação fixa, prevista no Dec. Lei $406 / 68\left(\right.$ art. $9^{\circ}, \mathbb{S} \mathbb{S} 1^{\circ}$ e $3^{\circ}$ ) e não revogada pela LC 116/2003, que permite a estipulação de alíquotas fixas ou variáveis em função da natureza do serviço, possível nas hipóteses de prestação de serviços sob a forma de trabalho pessoal do próprio contribuinte e serviços prestados por algumas sociedades de profissionais com assunção de responsabilidade pessoal.

Consoante o art. $3^{\circ}$ da LC $116 / 2003$, o serviço se considera prestado e o imposto devido no local do estabelecimento prestador ou no local do domicílio do prestador, exceto nas hipóteses previstas em seus incisos I a XXII, quando o imposto será devido no local da prestação do serviço. As hipóteses elencadas tratam de serviços passíveis de execução fora dos limites do município onde está localizado o estabelecimento prestador, situações nas quais o imposto será devido no local da efetiva prestação.
O sujeito passivo da obrigação principal é a pessoa obrigada ao pagamento do tributo. Pode ser o contribuinte (prestador do serviço - art. $5^{\circ}$ LC 116/2003) ou o responsável, isto é, aquele a quem, de acordo com o art. $6^{\circ}$ LC 116/2003, é atribuída a responsabilidade pelo recolhimento integral do ISS como tomador ou intermediário do serviço. A existência da figura do responsável facilita sobremaneira a fiscalização e arrecadação do ISS. Nesse sentido, no caso da mineração, as mineradoras assumem o papel de responsável tributário, sempre que possível, nos serviços que contratam de terceiros.

\section{Imposto sobre operações relativas à circulação de mercadorias e sobre prestações de serviços de transporte interestadual e intermunicipal e de comunicação (ICMS)}

O ICMS é de competência estadual e tem, como fato gerador, as operações relativas à circulação de mercadorias e prestações de serviços de transporte interestadual e intermunicipal e de comunicação, ainda que as operações e as prestações se iniciem no exterior (CF, art. 155, II). O ICMS é não cumulativo, compensando-se o que for devido em cada operação ou prestação com o montante cobrado nas operações anteriores pelo mesmo Estado ou pelo Distrito Federal (CF, art. $\left.153, \mathbb{S} 2^{\circ}, \mathrm{I}\right)$.

Para determinação do cálculo do imposto a recolher, adota-se o método do crédito fiscal, que procura, por meio da dedução do imposto pago na operação anterior, alcançar apenas a circulação mercantil líquida da empresa, ou seja, tributar apenas o valor adicionado por ela (Baleeiro, 2005).

Antes da promulgação da Constituição de 1988, os minerais tinham uma tributação especial, mediante o Imposto Único sobre Minerais (IUM). Com a nova Carta, o IUM foi extinto e as operações com minerais passaram a ser tributadas pelo ICMS. O IUM havia sido criado no intuito de proteger a produção de insumos básicos, como minerais e combustíveis, evitando que estados e municípios extrapolassem na tributação do setor que se buscava incentivar (Baleeiro, 2005). Essa preocupação se manteve na nova ordem constitucional, através do art. $155, \mathbb{3} 3^{\circ}$, ao dispor que, além dos impostos aduaneiros e do ICMS "nenhum outro imposto poderá incidir sobre operações relativas à energia elétrica, aos serviços de telecomunicações, aos derivados de petró- leo, aos combustiveis e minerais do País".

No ICMS, a participação municipal é de $25 \%$ do produto da arrecadação do Estado-Membro (art. 158, IV, CF), sendo que essas parcelas de receita serão creditadas conforme os seguintes critérios: I - três quartos, no mínimo, na proporção do valor adicionado nas operações relativas à circulação de mercadorias e nas prestações de serviços, realizadas em seus territórios; II - até um quarto, de acordo com o que dispuser lei estadual ou, no caso dos Territórios, lei federal.

Os critérios de participação municipal no produto da arrecadação do ICMS são estabelecidos pela Lei Complementar $n^{\circ} 63 / 90$, que, em seu art. $3^{\circ}, \mathbb{1} 1^{\circ}$, dispõe sobre o conceito de valor adicionado que "corresponderá, para cada Município, ao valor das mercadorias saídas, acrescido o valor das prestações de serviços, no seu território, deduzido o valor das mercadorias entradas, em cada ano civil". Trata-se, portanto, de um indicador econômico-contábil utilizado pelo Estado para calcular o repasse de receita do ICMS aos municípios. Espelha o movimento econômico e, consequentemente, o potencial que o município tem para gerar receitas públicas.

O cálculo do percentual de ICMS que será distribuído pelo Estado entre os municípios é baseado no percentual do valor adicionado em razão da produção econômica em cada município e o valor total apurado do Estado (art. $3^{\circ}, \mathbb{} 2^{\circ}, \mathrm{LC}$ 63/90). Esse índice corresponderá à média dos índices apurados nos dois anos civis imediatamente anteriores ao da apuração (art. $3^{\circ}, \mathbb{\$} 3^{\circ}$, LC 63/90).

Com relação à produção mineral, é importante ressaltar que as operações que destinem o minério para o exterior são isentas da cobrança do ICMS, por força do art. $3^{\circ}$, II, da Lei Kandir (Lei Complementar 87/96). No entanto, essa hipótese de isenção não exclui a consideração da produção mineral, ainda que exportada, para a mensuração do índice do valor adicionado do município, ou seja, o município não contribui para a arrecadação do Estado, mas recebe a partilha pelo que produziu.

Além da participação relativa ao valor adicionado, os municípios têm, ainda, participação nos restantes $25 \%$ de acordo com o que a dispuser a lei estadual, no caso de Minas Gerais, a Lei 18.030/2009. Entre os critérios estabelecidos pela lei, para a partilha dos restantes $25 \%$, há a previsão de beneficiar municípios mais populosos, os que são sede de estabelecimentos penitenciários e os que investem em educação, saúde, preservação do meio ambiente e os municípios mineradores. Essa lei reduziu a participação dos municípios mineradores, saindo de $0,11 \%$, do total de repasse do ICMS, previsto na Lei 13.803/2000, para $0,01 \%$.

Dessa forma, há uma redução na transferência do ICMS para os municípios mineradores. No entanto, essa partilha não atende a critérios lógicos, pois se fundamenta em parâmetros que não correspondem à realidade vigente (produção mineral de 1988 e IUM), através da seguinte fórmula:

$$
\text { Índice }=\frac{\text { Receita IUM do Município em } 1988}{\text { Soma da Receita IUM do Estado }} \times 100
$$




\section{Compensação financeira sobre a exploração mineral - CFEM}

O art. 20, inc. IX, da Constituição da República, insere entre os bens da União, os recursos minerais e assegura, no $\mathbb{S} 1^{\circ}$, aos Estados, ao Distrito Federal e aos municípios, bem como aos órgãos da administração direta da União, participação no resultado da extração de petróleo ou gás natural, de recursos hídricos para fins de geração de energia elétrica e de outros recursos minerais no respectivo território, plataforma continental, mar territorial ou zona econômica exclusiva, ou compensação financeira por essa extração.

Atendendo ao preceito constitucional, o legislador optou pela compensação financeira ao invés da participação no resultado da extração. Assim, foi instituída a Compensação Financeira sobre Exploração Mineral por meio da Lei 7.990/89, que estabelece:

Art. $1^{\circ}$. O aproveitamento de recursos hídricos para fins de geração de energia elétrica e dos recursos minerais, por quaisquer regimes previstos em lei, ensejará compensação financeira aos Estados, Distrito Federal e Municípios, a ser calculada, distribuída e aplicada na forma estabelecida em lei.

Trata-se, portanto, de espécie de royalty, ou seja, um pagamento de contraprestação pela extração de recursos naturais não renováveis de propriedade da União; entende, nesse sentido, a jurisprudência do STF (RE 228800-5 DF). No Brasil, o pagamento do royalty é baseado no faturamento líquido resultante da venda, nos termos da Lei 7.990/89:

\section{Resultados}

A Tabela 1 explana as principais fontes de recursos que compuseram a receita do município de Ouro Preto no
Art. $6^{\circ}$. A compensação financeira pela exploração de recursos minerais, para fins de aproveitamento econômico, será de até 3\% (três por cento) sobre o valor do faturamento líquido resultante da venda do produto mineral, obtido após a última etapa do processo de beneficiamento adotado e antes da sua transformação industrial.

O conceito de faturamento líquido é estabelecido na Lei 8001/90 (art. $2^{\circ}$ ), como "o total das receitas de vendas, excluídos os tributos incidentes sobre a comercialização do produto mineral, as despesas de transporte e as de seguro". Essa regra gera grandes incertezas e disputas judiciais sobre quais tributos e quais transportes são dedutíveis.

A regulamentação do pagamento da CFEM é apresentada pelo Decreto $\mathrm{n}^{\circ}$ 1, de 11 de janeiro de 1991, que, em seu art. 14, define que, para o cálculo da compensação financeira, a "atividade de exploração mineral é a retirada de substâncias minerais da jazida, mina, salina ou outro depósito mineral para fins de aproveitamento econômico."

O mesmo decreto define o fato gerador da CFEM (art.14) como sendo " $a$ saída por venda do produto mineral das áreas da jazida, mina, salina ou de outros depósitos minerais de onde provém, ou de quaisquer estabelecimentos, sempre após a última etapa do processo de beneficiamento adotado e antes de sua transformação industrial".

A Lei 8001/90 também define os percentuais da distribuição da compensação financeira entre os entes públicos, em seu artigo $2^{\circ}$ :

$\int 2^{\circ}$ A distribuição da compensação financeira de que trata este artigo será feita da seguinte forma:

I - 25\% (vinte e cincos por cento) para os Estados e o Distrito Federal.

II $-65 \%$ (sessenta e cinco por cento) para os municípios.

III - 3\% (três por cento) ao Ministério do Meio Ambiente.

IV - 3\% (três por cento) ao Ministério de Minas e Energia.

$V-4 \%$ (quatro por cento) ao Fundo Nacional de Desenvolvimento Tecnológico - FNDCT.

É relevante, portanto, a participação dos municípios na arrecadação da CFEM, que deveriam utilizar essa renda como forma de promoção de alternativas de desenvolvimento, dado o caráter finito das reservas minerais. No entanto, a única restrição imposta pela lei (Lei 7.990/89, art. $8^{\circ}$ ) sobre a aplicação dos recursos da CFEM é no sentido de vedar "a aplicação dos recursos em pagamento de divida e no quadro permanente de pessoal".

A ausência de políticas municipais de aplicação dessa renda gera a chamada "armadilha do caixa único", ou seja, essa receita pode não ser aplicada de acordo com sua finalidade - que seria a aplicação dos recursos em investimentos que objetivassem a diversificação produtiva e o desenvolvimento de capital humano (Enriquez, 2008).

período compreendido entre os anos de 2006 a 2010. A análise dos dados elencados demonstra a importância das

rendas objeto de estudo neste trabalho ISS, ICMS e CFEM - na composição da arrecadação municipal. Nesse universo,

\begin{tabular}{c|c|c|c|c|c}
\hline Receita & $\begin{array}{c}\text { Valores Brutos } \\
\mathbf{2 0 0 6}\end{array}$ & $\begin{array}{c}\text { Valores Brutos } \\
\mathbf{2 0 0 7}\end{array}$ & $\begin{array}{c}\text { Valores Brutos } \\
\mathbf{2 0 0 8}\end{array}$ & $\begin{array}{c}\text { Valores Brutos } \\
\mathbf{2 0 0 9}\end{array}$ & $\begin{array}{c}\text { Valores Brutos } \\
\mathbf{2 0 1 0}\end{array}$ \\
\hline ICMS & $\mathrm{R} \$ 58,934,683$ & $\mathrm{R} \$ 59,245,443$ & $\mathrm{R} \$ 67,859,375$ & $\mathrm{R} \$ 67,883,055$ & $\mathrm{R} \$ 90,188,175$ \\
\hline $\mathrm{CFEM}$ & $\mathrm{R} \$ 6,943,285$ & $\mathrm{R} \$ 6,516,051$ & $\mathrm{R} \$ 18,539,920$ & $\mathrm{R} \$ 8,433,850$ & $\mathrm{R} \$ 14,028,433$ \\
\hline FPM & $\mathrm{R} \$ 12,026,187$ & $\mathrm{R} \$ 13,963,672$ & $\mathrm{R} \$ 18,394,568$ & $\mathrm{R} \$ 17,621,389$ & $\mathrm{R} \$ 18,935,441$ \\
\hline ISSQN & $\mathrm{R} \$ 7,904,670$ & $\mathrm{R} \$ 10,393,702$ & $\mathrm{R} \$ 13,490,908$ & $\mathrm{R} \$ 10,056,276$ & $\mathrm{R} \$ 14,927,208$ \\
\hline Funde b & $\mathrm{R} \$ 7,213,951$ & $\mathrm{R} \$ 9,507,482$ & $\mathrm{R} \$ 13,151,757$ & $\mathrm{R} \$ 14,137,286$ & $\mathrm{R} \$ 16,188,963$ \\
\hline IPVA & $\mathrm{R} \$ 2,376,118$ & $\mathrm{R} \$ 2,781,471$ & $\mathrm{R} \$ 3,139,645$ & $\mathrm{R} \$ 3,478,637$ & $\mathrm{R} \$ 3,711,750$ \\
\hline Taxas & $\mathrm{R} \$ 848,154$ & $\mathrm{R} \$ 1,076,921$ & $\mathrm{R} \$ 1,211,351$ & $\mathrm{R} \$ 3,348,341$ & $\mathrm{R} \$ 2,595,308$ \\
\hline ITBI & $\mathrm{R} \$ 406,060$ & $\mathrm{R} \$ 423,638$ & $\mathrm{R} \$ 724,023$ & $\mathrm{R} \$ 566,885$ & $\mathrm{R} \$ 473,473$ \\
\hline ITR & $\mathrm{R} \$ 462,623$ & $\mathrm{R} \$ 335,996$ & $\mathrm{R} \$ 634,736$ & $\mathrm{R} \$ 1,226,197$ & $\mathrm{R} \$ 125,708$ \\
\hline IPTU & $\mathrm{R} \$ 434,023$ & $\mathrm{R} \$ 477,234$ & $\mathrm{R} \$ 513,793$ & $\mathrm{R} \$ 685,285$ & $\mathrm{R} \$ 1,065,756$ \\
\hline Outras & $\mathrm{R} \$ 17,499,962$ & $\mathrm{R} \$ 17,229,456$ & $\mathrm{R} \$ 22,801,945$ & $\mathrm{R} \$ 24,144,889$ & $\mathrm{R} \$ 31,500,496$ \\
\hline Total & $\mathrm{R} \$ 115,049,716$ & $\mathrm{R} \$ 121,951,066$ & $\mathrm{R} \$ 160,462,021$ & $\mathrm{R} \$ 151,582,063$ & $\mathrm{R} \$ 193,740,711$ \\
\hline
\end{tabular}

Tabela 1

Principais receitas do município de Ouro Preto (Prefeitura Municipal de Ouro Preto, 2011). 
destaca-se o ICMS, representando, aproximadamente, $45 \%$ do total arrecadado. Desse montante, o setor mineral ocupa papel de destaque. De acordo com dados disponibilizados pela Secretaria de Fazenda da Prefeitura de Ouro Preto, no ano de 2010, a atividade mineral representou aproximadamente $79 \%$ do valor adicionado fiscal do município.

Figura 1

Preço do minério de ferro por tonelada seca longa em US\$ - 2008 - Brasil/China

(IBRAM, 2010).

Figura 2

Evolução da produção de minério de ferro no Brasil (IBRAM, 2011).

\section{Discussão de resultados}

Considerando a CFEM e os percentuais de participação da produção mineral no ICMS e no ISS, chega-se ao seguinte quadro da Tabela 2 .

Conforme é possível observar, a arrecadação resultante da produção mineral no município de Ouro Preto variou entre $35 \%$ e $40 \%$ do total arrecadado

Tabela 2

Arrecadação mineral em Ouro Preto.
No que tange ao ISSQN, no ano de 2010, a arrecadação proveniente de serviços prestados a mineradoras representou montante de R \$ 8.016.375,00, correspondendo a cerca de $54 \%$ do total, de acordo com dados disponibilizados pela Secretaria de Fazenda da Prefeitura de Ouro Preto.

Ainda é possível constatar o expres-

sivo aumento da arrecadação no período, com exceção do ano de 2009, que foi marcado pela crise financeira internacional de 2008, que impactou a produção mineral mundial. Esse movimento de crescimento da arrecadação acompanha a evolução dos preços do minério de ferro e de sua produção no país, conforme o demonstram as Figuras 1 e 2.
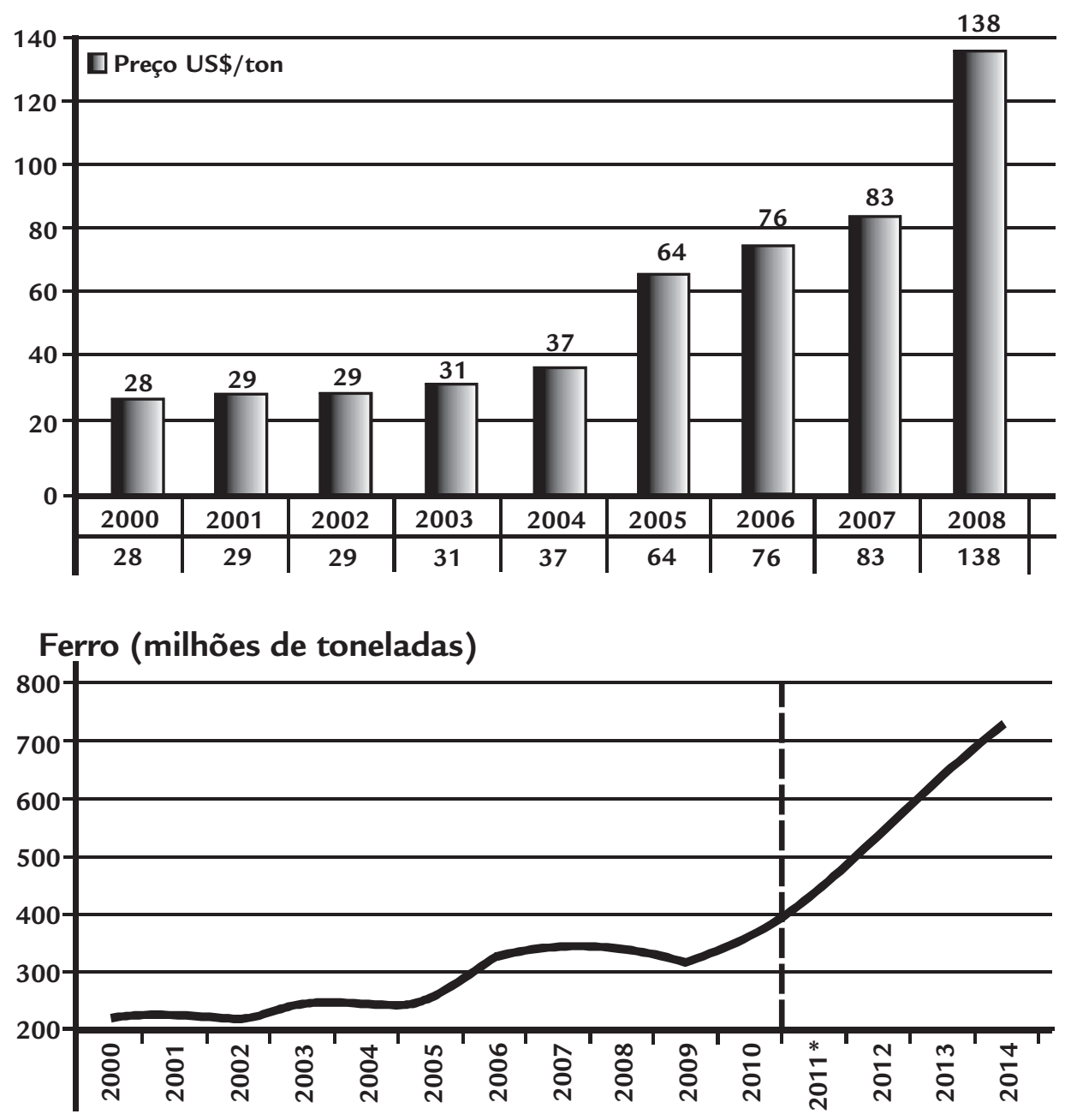

nos anos em análise, o que demonstra a dependência da receita da administração local do setor.

Vale ressaltar que o ICMS é a principal fonte de receita de Ouro Preto, sendo que essa situação é resultado da relevante participação da indústria mineral. Isto ocorre, também, com outros municípios mineradores, fato que se destaca com a relevância do repasse do ICMS na composição da receita desses municípios, ainda quando comparados com municípios com atividade industrial considerável como Juiz de Fora e Sete Lagoas, mostrada na Tabela 3.

\begin{tabular}{c|c|c|c}
\hline Receita & Valor 2008 & Valor 2009 & Valor 2010 \\
\hline ICMS (R\$) & 40.206 .685 & 40.220 .710 & 53.436 .493 \\
\hline CFEM (R\$) & 18.539 .920 & 8.433 .850 & 14.028 .433 \\
\hline ISS (R\$) & 7.244 .618 & 5.400 .220 & 8.016 .375 \\
\hline Arrecadação total através da mineração (R\$) & 65.991 .223 & 54.054 .780 & 75.481 .301 \\
\hline Percentual sobre o total arrecadado (\%) & 41,13 & 35,66 & 38,96 \\
\hline
\end{tabular}




\begin{tabular}{c|c|c|c|c|c}
\hline População & Município & $\begin{array}{c}\text { Receita } \\
\text { Tributária (\%) }\end{array}$ & $\begin{array}{c}\text { Fundo de Participação } \\
\text { dos Municípios (\%) }\end{array}$ & $\begin{array}{c}\text { ICMS } \\
\text { (\%) }\end{array}$ & $\begin{array}{c}\text { Outras } \\
\mathbf{( \% )}\end{array}$ \\
\hline 526.706 & Juiz de Fora & 23,7 & 5,8 & 15,0 & 55,5 \\
\hline 225.358 & Sete Lagoas & 19,8 & 15,8 & 20,9 & 43,6 \\
\hline 216.099 & Divinópolis & 15,0 & 14,2 & 16,0 & 54,8 \\
\hline 128.572 & Barbacena & 11,4 & 14,4 & 10,0 & 64,2 \\
\hline 114.579 & Cons. Lafaiete & 10,6 & 25,7 & 13,1 & 50,6 \\
\hline 110.419 & Itabira & 9,9 & 9,8 & 38,6 & 41,6 \\
\hline 76.608 & Nova Lima & 30,6 & 8,1 & 30,8 & 30,5 \\
\hline 69.495 & Ouro Preto & 12,6 & 13,4 & 51,2 & 22,8 \\
\hline 54.689 & Mariana & 9,7 & 11,8 & 43,0 & 35,5 \\
\hline 9.738 & São Gonçalo Rio Abaixo & 12,2 & 6,8 & 36,5 & 44,4 \\
\hline
\end{tabular}

Tabela 3

Composição da receita de municípios em 2009 (Borges \& Vilela, 2010).

\section{Conclusões}

Diante do exposto, fica evidente a dependência da arrecadação de Ouro Preto do setor mineral. Essa dependência é resultado do acréscimo proporcionado pelas rendas da CFEM e, principalmente, pela transferência do ICMS. A Tabela 3 ressalta que essa dependência não é característica exclusiva do município estudado, mas que ela marca a vida financeira dos demais municípios mineradores.

A importância do ICMS, na composição dessa renda, nos leva a concluir que a aplicação dos recursos da CFEM poderia ser condicionada a investimentos em diversificação produtiva e desenvolvimento de capital humano, tendo em vista a característica de exauribilidade dos recursos minerais. Nesse sentido, medidas podem ser tomadas como, por exemplo, a criação de fundos para o fomento de atividades produtivas através do produto da arrecadação da CFEM. É necessário, ainda, priorizar os investimentos nas áreas mais impactadas pela mineração.

Além disso, é necessário que haja uma reflexão sobre a composição da receita de Ouro Preto, para que seja elaborada uma política tributária consistente. Como exemplo da inconsistência da arrecadação atual, tem-se o valor arrecadado de IPTU, que correspondeu a apenas $0,45 \%$ do total arrecadado em 2009, apresentando uma evolução para $0,55 \%$ em 2010. Outros impostos, como ITR e o IPVA, têm comportamentos que podem ser influenciados pelo desempenho da mineração regional, bem como pela eficácia do sistema de planejamento e de gestão tributária do município. Tais impostos deveriam ser objeto de estudo da administração municipal.

Um dos fatores que podem justificar a acomodação do município à baixa arrecadação do IPTU é a alta arrecadação proveniente da mineração. No entanto, mesmo com a arrecadação em bons termos, é necessário que os tributos originados de fonte de arrecadação própria representem um papel mais relevante na composição da receita, no intuito de fazer face à flutuação dos preços no mercado de commodities e de minorar a dependência do município ao setor mineral.

A crise financeira internacional de 2008 pode exemplificar o perigo dessa dependência, ainda que seus efeitos tenham se limitado ao ano de 2009. Na hipótese de uma crise de maior duração, a consequência seria o prejuízo a serviços públicos essenciais e, necessariamente, uma tendência à ampliação da tributação própria do município em um período de recessão.

Um aspecto que poderia contribuir para a discussão é a análise da economia mineral sob a perspectiva de cada município minerador. Os dados do DNPM têm, como foco, a perspectiva nacional e são insuficientes para este tipo de pesquisa. Uma possibilidade é a realização desses estudos por Associações de Municípios Mineradores como a AMIB, AMIG e AMMEPA.

Assim como outras iniciativas de outras localidades, sugere-se destinação de parte da receita tributária originária da mineração para constituição de um fundo de apoio ao desenvolvimento de infraestruturas impulsionadoras da diversificação e verticalização da matriz produtiva regional.

Concluindo, a tributação representa verdadeira oportunidade de desenvolvimento para os municípios com produção mineral relevante. Mas é necessário o acompanhamento e o desenvolvimento de políticas de diversificação de atividades produtivas, para fazer face às características do setor mineral, sobretudo a situação da transitoriedade das receitas advindas dessa fonte. Há que se ressaltar, também, os riscos decorrentes da flutuação dos preços das commodities no mercado internacional, inclusive do minério de ferro, que impulsiona o município em destaque.

Assim, é imprescindível que políticas públicas sejam adotadas com o objetivo de se ampliar a matriz produtiva do município e de se estabelecer uma política tributária em consonância com as características da economia mineral local.

\section{Referências bibliográficas}

BALEEIRO, A. Direito tributário brasileiro (atualizada porMisabel Abreu Machado Derzi). Rio de Janeiro: Forense, 2005. 1120 p.

BORGES, A. J. M., VILLELA, T. M. C. (Org.). Finanças dos municípios mineiros. V6. Vitória: Aequus Consultoria, 2010. 148 p.

CARRAZZA, R.A.. Curso de direito constitucional tributário. São Paulo: Malheiros, 2004.1152p.

ENRIQUEZ, Maria Amélia Rodrigues da Silva. Mineração: maldição ou dádiva? Os dilemas do desenvolvimento sustentável a partir de uma base mineira. São Paulo: Signus Editora, 2008. 396p. 
FUNDAÇÃO JOÃO PINHEIRO. Perfil da economia mineral do Estado de Minas Gerais - 2001 a 2005. Belo Horizonte, 2009. 205 p.

HERRMANN, H. A mineração sob a óptica legal. In: LINS, F. A. F., LOUREIRO, F. E. V. L., ALBUQUERQUE, G. A. S. Cavalcanti (Org.). Brasil 500 anos: a construção do Brasil e da América Latina pela mineração. Rio de Janeiro: CETEM/MCT, 2000. p. 165-178.

INSTITUTO BRASILEIRO DE MINERAÇÃO. Boletim de informações $e$ de análises da economia mineral brasileira - $5^{a}$ edição, 2010. (Disponível em: http:// www.ibram.org.br/sites/1300/1382/00000284.pdf. Acessado em: 25/05/2011).

INSTITUTO BRASILEIRO DE MINERAÇÃO. Consolidação dos dados de 2010 e perspectivas da indústria mineral brasileira e de Minas Gerais. (Disponível em: http://www.ibram.org.br/sites/1300/1382/00001164.ppt. Acessado em: 25/05/2011).

MONTEIRO, M. A. Amazônia: mineração, tributação e desenvolvimento regional. Belém, Novos Cadernos NAEA, v. 7, n. 2, 2004. p. 159-186.

Artigo recebido em 26 de maio de 2011. Aprovado em 03 de outubro de 2011.

www.rem.com.br

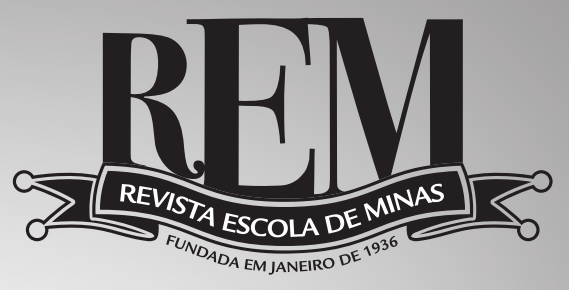

Divulgue sua empresa e seus produtos para os formadores de opinião do setor mínero-metalúrgico.

\section{ANUNCIE NA REM - REVISTA ESCOLA DE MINAS.}

Pedidos de inserção, negociações e consultas: RBC EDITORAÇÃO ELETRÔNICA Luciano Borba (31) 35514730 diretor.comercial@rem.com.br 